\title{
Influence of carbon nanotubes support on the morphology of $\mathrm{Fe}_{3} \mathrm{O}_{4}$ nanoparticles
}

\author{
F. Zabihi $\cdot$ F. Taleshi $\cdot$ A. Salmani $\cdot$ \\ A. Pahlavan $\cdot$ N. Dehghan-niarostami • \\ M. M. Vadadi
}

Received: 5 April 2014/ Accepted: 28 April 2014/Published online: 16 May 2014

(C) The Author(s) 2014. This article is published with open access at Springerlink.com

\begin{abstract}
In this paper, the effects of carbon nanotubes as a support to the morphology and size of $\mathrm{Fe}_{3} \mathrm{O}_{4}$ magnetic nanoparticles have been investigated. The synthesis of $\mathrm{Fe}_{3} \mathrm{O}_{4} /$ CNTs nanocomposite powder was performed by the direct precipitation method through ferric chloride (II) and (III) at room temperature. The prepared samples were analyzed by X-ray diffraction spectra, Fourier transform infrared spectroscopy, scanning electron microscopy and transmission electron microscopy. The results demonstrated considerable changes in the $\mathrm{Fe}_{3} \mathrm{O}_{4}$ nanoparticle size, also the morphology of $\mathrm{Fe}_{3} \mathrm{O}_{4} / \mathrm{CNTs}$ nanocomposite powder from agglomerative into rode shape.
\end{abstract}

Keywords Carbon nanotube - Magnetic nanoparticles · Morphology $\cdot$ Nanocomposite $\cdot$ Direct precipitation

\section{Introduction}

Extensive investigations' have been conducted on improving the synthesis and characterization of magnetic nanoparticle due to their possessing unique properties and their wide application in the various industries (Tjong and

F. Zabihi - A. Salmani - A. Pahlavan - N. Dehghan-niarostami Department of Physics, Sari Branch, Islamic Azad University, Sari, Iran

F. Taleshi $(\bowtie)$

Department of Applied Science, Qaemshahr Branch, Islamic

Azad University, PO Box 163, Qaemshahr, Iran

e-mail: far.taleshi@gmail.com

M. M. Vadadi

Department of Chemistry, Payam Noor University, PO Box 19395-697, Tehran, Iran
Chen 2004; Laurent et al. 2008; Zhang et al. 2006; He et al. 2008). Among the various magnetic nanoparticles, $\mathrm{Fe}_{3} \mathrm{O}_{4}$ the nanoparticle has leading properties such as chemical stability, high dispersion in liquid circumferences, good bio-adaptability, stability in various physiological conditions and low dissolubility (Yan et al. 2009; Tartaj et al. 2003; Qiao et al. 2009; Ghandoor et al. 2012).

These kinds of nanoparticles have been successfully used and applied in magnetic recorders (Laurent et al. 2008; Ghandoor et al. 2012), cancer therapy (He et al. 2008; Figuerola et al. 2010) storing information processes (Yan et al. 2009), magnetic resonance imaging (MRI) (Qiao et al. 2009), and drug targeting (Figuerola et al. 2010).

Moreover, since the discovery of carbon nanotubes (CNTs), they are being used as a support for controlling the size and morphology of nanoparticles (Cheng et al. 2008). Therefore, every effort is being made to allow the placement of metal nanoparticles, metal oxides and semiconductors nanoparticles onto the nanotubes (Cheng et al. 2008; Ramin and Taleshi 2013). Due to the high aspect ratio of the carbon nanotubes, they prevent the agglomerating of the particles and increase their applicability considerably (Cheng et al. 2008; Ramin and Taleshi 2013; Liu et al. 2009). However, there are two basic problems in the preparation of such a composite. The first problem is spinning and the varied diffusion rate of the nanotube in the composite. The second is the suitable non-adhesion of the carbon nanotube surface with synthesized nanoparticles, which is due to a strong covalent bond between the considered nanoparticle and the white carbon nanotubes (Taleshi and Hosseini 2012). As a result, the nanotubes surface activation makes a suitable reaction between their surfaces, and with the nanoparticle, which is necessity (Taleshi and Hosseini 2012; Wang et al. 2010). The CNTs 
activation of the surface is typically performed by a chemical oxidation process and produces the formation of various functional groups such as $\mathrm{COOH}, \mathrm{C}-\mathrm{O}, \mathrm{C}=\mathrm{O}$ and OH (Taleshi and Hosseini 2012; Wang et al. 2010). These chemical bonds could act as sites for nucleation of nanoparticle.

The effects of CNTs as a support for size and morphology of $\mathrm{Fe}_{3} \mathrm{O}_{4}$ nanoparticles prepared by direct precipitating were further explored in this research paper. Fourier transform infrared spectroscopy (FT-IR, Shimadzu-8400 s) has been used for the study of functional groups on the CNTs surface, as well as X-ray diffraction (XRD, Pw, 1800, Philips) was applied for identifying the crystalline structure of the nanoparticles. The morphology of $\mathrm{Fe}_{3} \mathrm{O}_{4}$ nanoparticle powder and $\mathrm{Fe}_{3} \mathrm{O}_{4} / \mathrm{CNTs}$ nanocomposite powder has been analyzed by the scanning electron microscope (SEM, Philips, SE, 3000K, and 15X) and transmission electron microscope (TEM, Philips, CM10, and HT100 kV). The results showed that carbon nanotubes had decreased considerably and the size of the $\mathrm{Fe}_{3} \mathrm{O}_{4}$ magnetic nanoparticles changed in morphology in the powder forming an agglomerative into a fibrous shape.

\section{Experimental process}

Iron (II) chloride tetrahydrate $\left(\mathrm{FeCl}_{2} \cdot 4 \mathrm{H}_{2} \mathrm{O}, 99 \%+\right)$, Iron (III) chloride hexahydrate $\left(\mathrm{FeCl}_{3} \cdot 6 \mathrm{H}_{2} \mathrm{O},>99 \%\right)$, ammonium hydroxide solution $\left(\mathrm{NH}_{4} \mathrm{OH}\right)$, carbon nanotube (CNTs, Neutrino china, pure percentage $99 \%, 20 \mathrm{~nm}$ $<\mathrm{d}<30 \mathrm{~nm}$ ), sulfuric acid $\mathrm{H}_{2} \mathrm{SO}_{4}$ and nitric acid $\mathrm{HNO}_{3}$ were used for preparing the samples for this research.

The synthesis of $\mathrm{Fe}_{3} \mathrm{O}_{4}$ nanoparticles was conducted by direct precipitating method for this reason, we initially poured $4 \mathrm{mmol}(1.08 \mathrm{~g}) \mathrm{FeCl}_{3} \cdot 6 \mathrm{H}_{2} \mathrm{O}$ and $2 \mathrm{mmol}(0.4 \mathrm{~g})$ $\mathrm{FeCl}_{2} \cdot 4 \mathrm{H}_{2} \mathrm{O}$ into the rotating beaker containing $50 \mathrm{ml}$ distilled water and prepared a brown solution. Then $2.5 \mathrm{ml}$ of ammonium hydroxide was quickly added to the solution, during rotation black sediment resulted. We then poured the obtained sediment through filter paper and washed it with distilled water. The resulting sample was dried in the oven at $110^{\circ} \mathrm{C}$ for $3 \mathrm{~h}$.

For application of the reagent to the CNTs surface, a required amount of CNTs was mixed with a $6 \mathrm{M}$ composite solution of nitric and sulfuric acid and placed under the ultrasonic waves for $1 \mathrm{~h}$, the resulting product was rotated over the hotplate at $80{ }^{\circ} \mathrm{C}$ for $2 \mathrm{~h}$. We poured the sample through filter paper to neutralize the acidic phase form, then washed the sample with distilled water several times to reach to a neutralized state $(\mathrm{pH}=7)$.

To synthesize the nanocomposite powder $\mathrm{Fe}_{3} \mathrm{O}_{4} / \mathrm{CNTs}$ to various composition ratios of $2 / 1,1 / 1,1 / 2,1 / 4$ and $1 / 8$, we poured $0.25 \mathrm{~g}$ of the CNTs with the applied regent into $50 \mathrm{ml}$ of distilled water and placed it under ultrasonic waves for $10 \mathrm{~min}$; we then added a required amount of ferric chloride salts to the solution which contained the carbon nanotubes, for each composition ratio, the obtained solution was rotated by a magnetic mixer at room temperature. Subsequently, after $5 \mathrm{~min}$ of rotating the solution, $2.5 \mathrm{ml}$ of ammonium hydroxide was added to the obtained solution and was separated by pouring the solution through a filter paper, the resulting samples were dried in the oven at $110{ }^{\circ} \mathrm{C}$ for $2 \mathrm{~h}$.

\section{Results and discussion}

Figure 1 represents the XRD patterns of pure $\mathrm{Fe}_{3} \mathrm{O}_{4}$ nanoparticles and $\mathrm{Fe}_{3} \mathrm{O}_{4} / \mathrm{CNTS}$ nanocomposite with various composition ratios. In Fig. 1a, the peaks placed on $2 \theta$ of $18.4^{\circ}, 30.2^{\circ}, 35.6^{\circ}, 43.2^{\circ}, 53.6^{\circ}, 57.1^{\circ}, 62.6^{\circ}, 73.9^{\circ}$ and $74.2^{\circ}$ represent the synthesis of magnetite phase $\left(\mathrm{Fe}_{3} \mathrm{O}_{4}\right)$ with reversed spin cubic structure that is, respectively, the reflex of crystalline planes (111), (220), (311), (400), (422), (511), (440) and (622) (Wang et al. 2010; Hoa et al. 2009). In this chemical structure, oxygen ions are in a cubic crystalline arrangement and the iron ions have occupied the octahedral and tetrahedral (Han et al. 1994). Moreover, the peaks being sharp like represents the crystalline order and high crystalline structure of $\mathrm{Fe}_{3} \mathrm{O}_{4}$ nanoparticles, there were no additional peaks, due to the existing impurity in the prepared powder.

In the spectra obtained from $\mathrm{Fe}_{3} \mathrm{O}_{4} / \mathrm{CNTs}$ nanocomposite powders with various ratios (Fig. $1 \mathrm{~b}-\mathrm{f}$ ), the $2 \theta=25.9^{\circ}$, $42.9^{\circ}$ as related to reflex of geraphen planes of carbon nanotubes in (002) and (100) direction, respectively (Taleshi and Hosseini 2012). Investigation of the sample spectra of Fig. 1c-f shows that the heights of peaks related to this nanotubes have reduced by reduction of $\mathrm{Fe}_{3} \mathrm{O}_{4}$ concentration and its width has increased. These changes indicated the considerable reduction of $\mathrm{Fe}_{3} \mathrm{O}_{4}$ nanoparticles size. On the other hand, the height of peaks related to carbon nanotubes at $2 \theta=25.9^{\circ}$ and $42.9^{\circ}$ did increased. This increase could be due to the reduction of $\mathrm{Fe}_{3} \mathrm{O}_{4}$ concentration on the CNTs surface and more exposure to the geraphen planes in the beam of X-ray. Studying the spectra of samples (Fig. 1c-f) shows that the width of basic peak related to $\mathrm{Fe}_{3} \mathrm{O}_{4}$ nanoparticles has increased by increasing the $\mathrm{Fe}_{3} \mathrm{O}_{4}$ concentration and the separation and visibility of peaks improved. The mentioned results represented the nanoparticles size that increased, but the width of peaks was associated to the carbon nanotubes decreasing.

According to maximum peak of XRD at $2 \theta=35.8^{\circ}$, the sizes of nanoparticles calculated by Scherrer formula following as (Venkateswarlu et al. 2010): 
Fig. 1 XRD spectra from various synthesized samples; pure $\mathrm{Fe}_{3} \mathrm{O}_{4}$ nanoparticles (a) and $\mathrm{Fe}_{3} \mathrm{O}_{4} / \mathrm{CNTs}$ nanocomposite powder with different weight ratios of $2 / 1$ (b), 1/1 (c), 1/2 (d), 1/4 (e) and $1 / 8(f)$

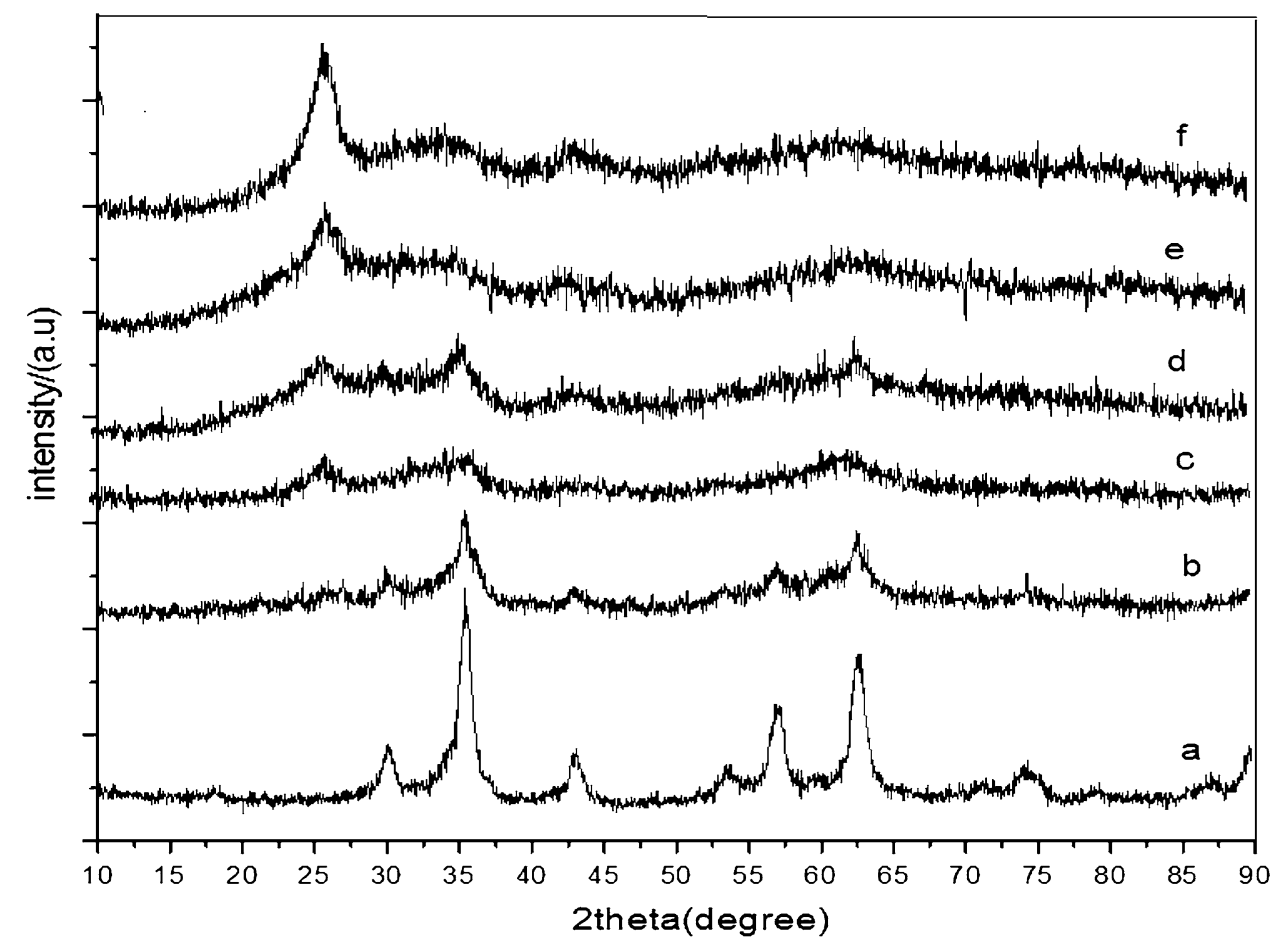

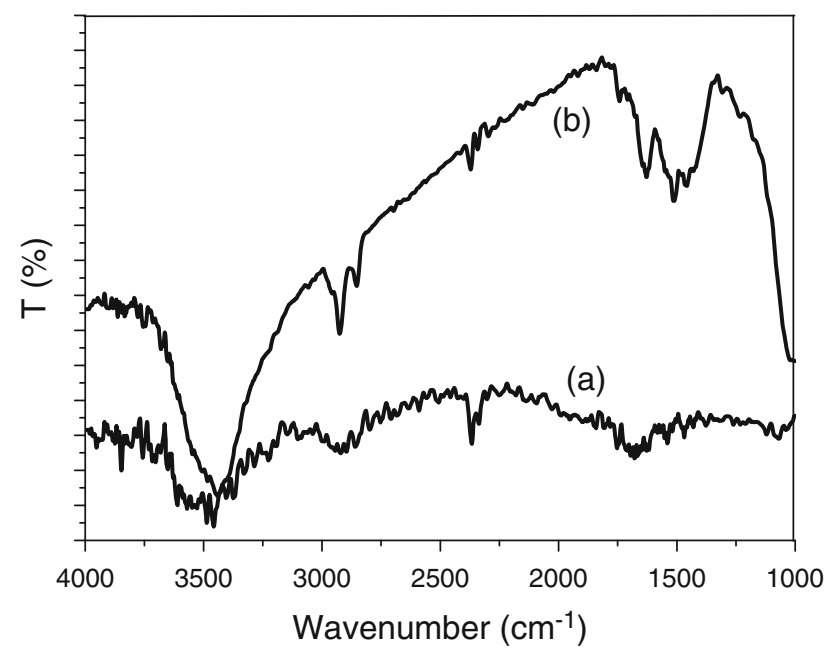

Fig. 2 FT-IR spectra from initial $(a)$ and purified CNTs $(b)$

$D=\frac{K \cdot \lambda}{\beta \cdot \cos \theta}$

where $K$ is Scherrer constant (about 0.9 ), $\lambda$ is the $\mathrm{X}$-ray wave length equal to $1.54 \AA, \theta$ is position of the maximum peak in term of the degree and $\beta$ is semi-width of spectra in the half of maximum peak (FWHM) in term of radian.

Results of calculations show that average of nanoparticles sizes for weight ratio of 1/0, 2/1, 1/1, 1/2, 1/4 and 1/8 is, respectively, 5.1, 2.7, 1.7, 1.5, 1.3 and $1.2 \mathrm{~nm}$.

To investigate the influence of the acidification process on the nanotubes surface and to study the reagent groups prepared from carbon nanotubes before and after purification process, the FT-IR spectra were prepared (Fig. 2). The FT-IR spectra from CNTs purified (Fig. 2a), over to initial CNTs (Fig. 2b), and the presence of some absorptive peaks reflect the formation of binding between the reagent groups placed on the carbon nanotubes through ultrasonic and acidification processes in $\mathrm{H}_{2} \mathrm{SO}_{4}$ and $\mathrm{HNO}_{3}$ acids. These reagent groups include $\mathrm{O}-\mathrm{C}=\mathrm{O}{ }^{\prime} \mathrm{C}-\mathrm{O}-\mathrm{O}{ }^{\prime} \mathrm{C}-\mathrm{O}$ and $\mathrm{C}=\mathrm{O}$, which respectively related to $1,210,1,415,1,475$ and $1,720 \mathrm{~cm}^{-1}$ wavelengths (Taleshi and Hosseini 2012). The above reagent groups have an important role in nucleation and formation of $\mathrm{Fe}_{3} \mathrm{O}_{4}$ nanoparticles. Due to a strong chemical binding and the binding between ions of iron atom with reagent groups of $\mathrm{O}-\mathrm{C}=\mathrm{O}{ }^{\prime} \mathrm{C}-\mathrm{O}-\mathrm{O}{ }^{\prime} \mathrm{C}-\mathrm{O}$ and $\mathrm{C}=\mathrm{O}$ placed on the carbon nanotubes surface, $\mathrm{Fe}_{3} \mathrm{O}_{4} /$ CNTs will form.

In Fig. 3, SEM images of prepared pure $\mathrm{Fe}_{3} \mathrm{O}_{4}$ nanoparticles (Fig. 3a) and $\mathrm{Fe}_{3} \mathrm{O}_{4} / \mathrm{CNT}$ s nanocomposite powder (Fig. 3b-f) with various weight ratios of $2 / 1,1 / 1,1 / 2,1 / 4$ and $1 / 8$ are showed. SEM images of pure $\mathrm{Fe}_{3} \mathrm{O}_{4}$ nanoparticles (Fig. 3a), represent the high assembly of synthesized nanoparticles. This high agglomeration could be due to synthesis of nanoparticles in the liquid medium and because they were small the nanoparticles, due to the surface effects, had a high tendency for surface adhesion with the adjacent nanoparticles. SEM images of $\mathrm{Fe}_{3} \mathrm{O}_{4} /$ CNTs nanocomposite powder (Fig. 3b-f) demonstrated that nanoparticles have different morphologies in agglomerating amount, irrespective to reaction condition. The size of nanoparticles was reduced with the increase of the concentration of carbon nanotube support in composite, 

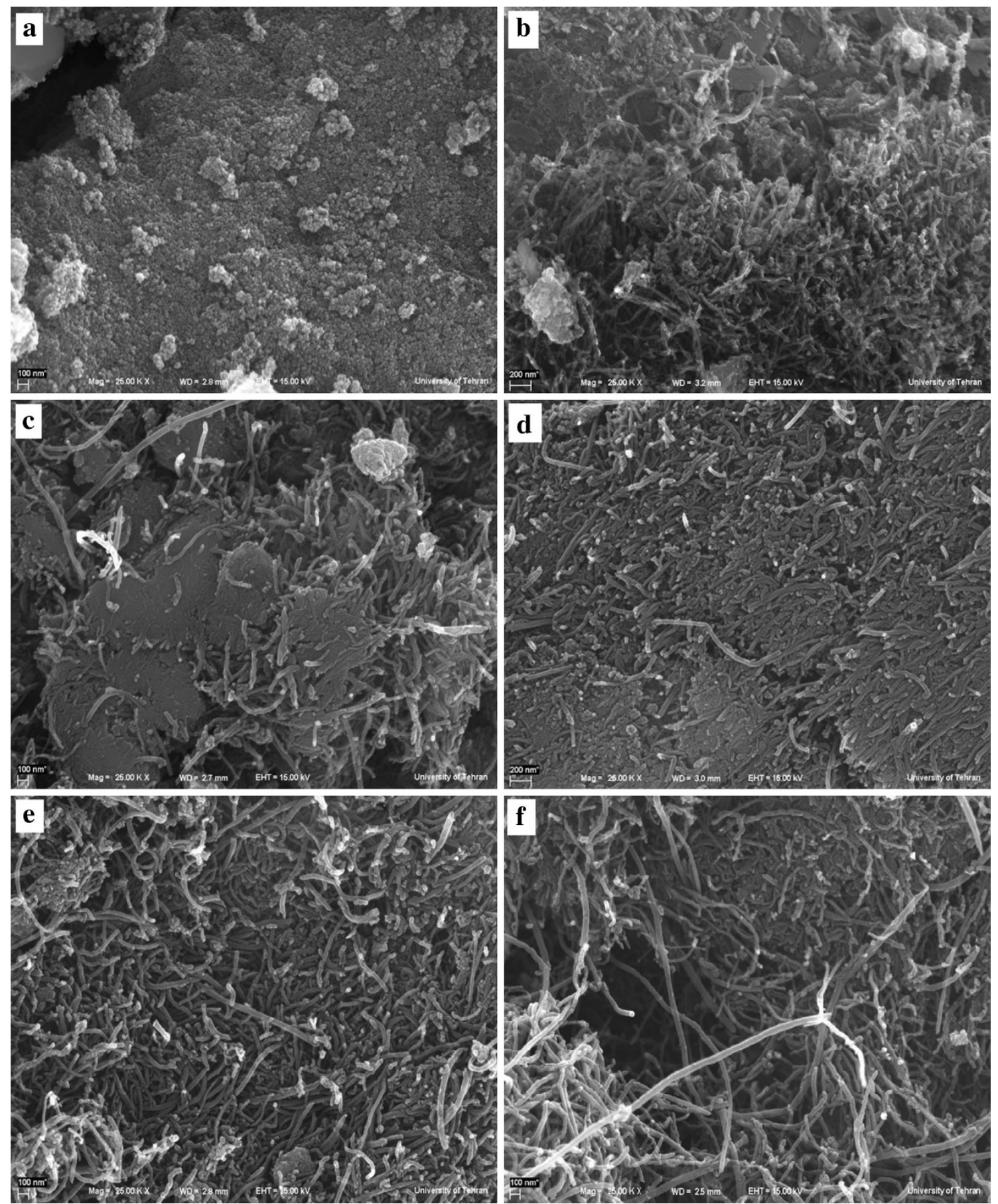

Fig. 3 SEM images of pure $\mathrm{Fe}_{3} \mathrm{O}_{4}$ nanoparticles (a); $\mathrm{Fe}_{3} \mathrm{O}_{4} / \mathrm{CNTs}$ nanocomposite powder with weight ratio of; 2/1 (b), 1/1 (c), 1/2 (d), 1/4 (e), and $1 / 8$ (f). (The magnification of all images is $\times 25 \mathrm{k}$ )

and the agglomerations of the particles were reduced considerably. Thus, the change of $\mathrm{Fe}_{3} \mathrm{O}_{4}$ nanoparticles concentration ratio to carbon nanotubes has a bad fundamental influence on the morphology and sizes of nanocomposite, consequently the prepared powders were converted from agglomerative state of nanoparticles (at weight ratio of $2 / 1,1 / 1$ ) into a nanorode state (at $1 / 8$ ratio). Synthesis of $\mathrm{Fe}_{3} \mathrm{O}_{4} / \mathrm{CNTs}$ nanocomposite into a fibrous state and their homogenous distribution on the nanotubes surface could change their physical and chemical properties considerably, and show better performance in the industrial application. 

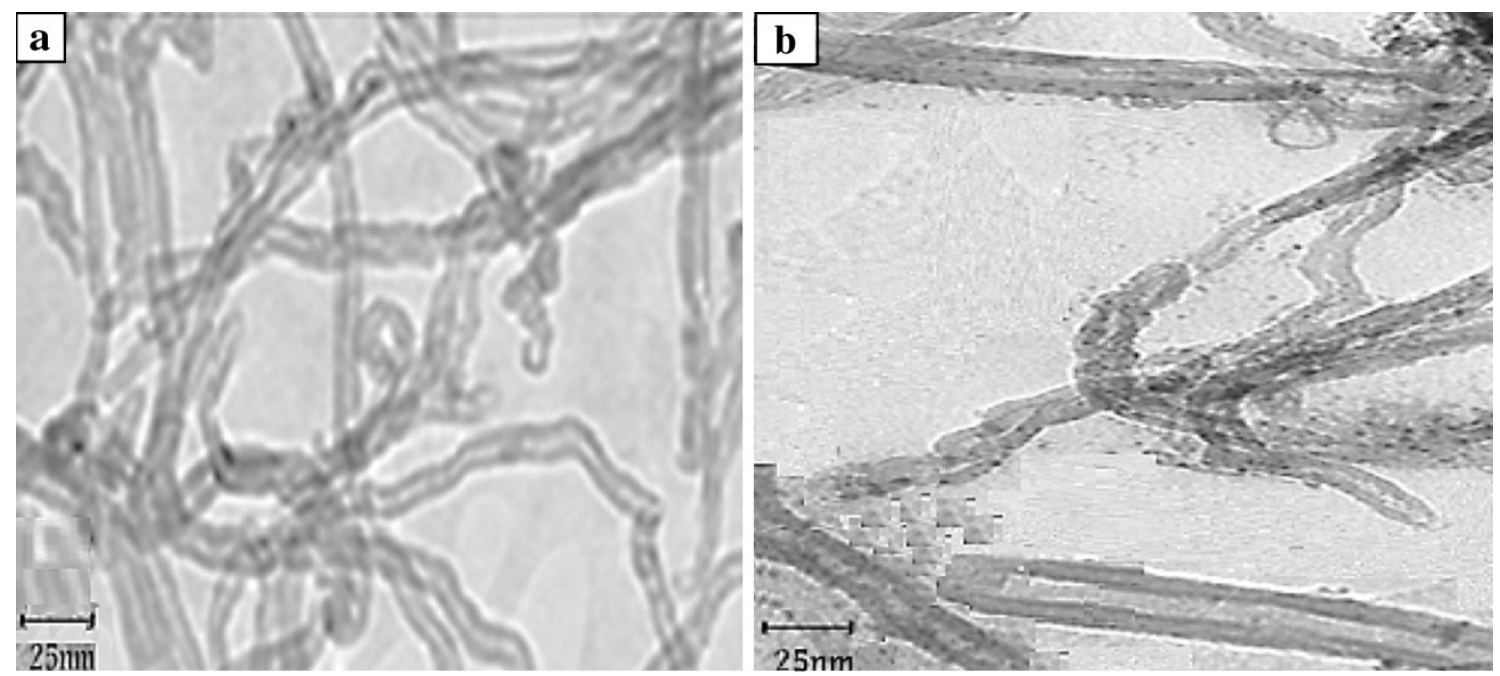

Fig. 4 TEM images of initial pure nanotubes (a), and synthesized $\mathrm{Fe}_{3} \mathrm{O}_{4} / \mathrm{CNTs}$ nanocomposite powder (b) with $1 / 8$ weight ratio

Figure 4 represents the images of TEM prepared from pure carbon nanotubes and prepared $\mathrm{Fe}_{3} \mathrm{O}_{4}$ /CNTs nanocomposite with 1/8 ratio. According to Fig. 4a, image of the carbon nanotube was shown after the reagent processing, in which no covering on the surface or in nanotubes was observed. However, the image of $\mathrm{Fe}_{3} \mathrm{O}_{4} /$ CNTs nanocomposite (Fig. 4b) showed $\mathrm{Fe}_{3} \mathrm{O}_{4}$ nanoparticles with round and separated geometrical shapes, and with very small improper dimensions, adhering to the nanotubes surface.

\section{Conclusion}

Results of X-ray diffraction spectra show that the application of carbon nanotubes caused a considerable reduction of peaks height of the $\mathrm{Fe}_{3} \mathrm{O}_{4}$ nanoparticles and an increase of their widths, consequently reducing the nanoparticles sizes. Also, we reduced the high agglomeration of synthesized $\mathrm{Fe}_{3} \mathrm{O}_{4}$ nanoparticles in the liquid medium, by applying the carbon nanotubes. Thus, the presence of the carbon nanotubes as a support for increasing $\mathrm{Fe}_{3} \mathrm{O}_{4}$ nanoparticles, in addition to reduction of nanoparticles size, has produced a change in the morphology of the prepared powder from agglomerative to a fibrous state. TEM images revealed the formation of nanoparticles on the purified carbon nanotubes surface, and this adhesion could be a document suitable for the reagent processing of the nanotubes surface under the acidification process.

Acknowledgments The authors would like to acknowledge the Islamic Azad University of Qaemshahr, Islamic Azad University of Sari and Iranian National Nanotechnology Initiation Council (INNIC) for their financial support of this project.
Open Access This article is distributed under the terms of the Creative Commons Attribution License which permits any use, distribution, and reproduction in any medium, provided the original author(s) and the source are credited.

\section{References}

Cheng JP, Zhang XB, Yi GF, Ye Y, Xia MS (2008) Preparation and magnetic properties of iron oxide and carbide nanoparticles in carbon nanotube matrix. J Alloy Compd 445:5-9

Figuerola A, Corato RD, Manna L (2010) From iron oxide nanoparticles towards advanced iron-based inorganic materials designed for biomedical applications. Pharmacol Res 62: 126-143

Ghandoor HE, Zidan HM, Khalil MMH, Ismail MIM (2012) Synthesis and some physical properties of magnetite $\mathrm{Fe}_{3} \mathrm{O}_{4}$ nanoparticles. Int J Electrochem Sci 7:57734-57745

Han DH, Wang JP, Luo HL (1994) Crystallite size effect on saturation magnetization of fine ferromagnetic particles. J Magn Magn Mater 136:176-182

He Q, Zhang Z, Xiongm J (2008) A novel biomaterial- $\mathrm{Fe}_{3} \mathrm{O}_{4}: \mathrm{TiO}_{2}$ core-shell nano particle with magnetic performance and high visible light photocatalytic activity. Optic Mater 31:380-384

Hoa TM, Dung TT, Danh TM, Duc NH, Chien DM (2009) Preparation and characterization of magnetic nanoparticles coated with polyethylene glycol. J Phys Conf Ser 187:012048

Laurent S, Forge D, Port M, Roch A, Robic C, Elst LV, Muller RN (2008) Magnetic iron oxide nanoparticles: synthesis, stabilization, vectorization, physicochemical characterizations, and biological applications. Chem Rev 108:2064-2110

Liu Y, Jiang W, Li S, Li F (2009) Electrostatic self-assembly of $\mathrm{Fe}_{3} \mathrm{O}_{4}$ nanoparticles carbon nanotubes. Appl Surf Sci 255:7999-8002

Qiao RR, Yang CH, Gao MY (2009) Superparamagnetic iron oxide nanoparticles: from preparations to in vivo MRI applications. J Mater Chem 19:6274-6293

Ramin M, Taleshi F (2013) The effect of carbon nanotubes as a support on morphology and size of silver nanoparticles. Int Nano Lett. doi:10.1186/2228-5326-3-32 
Taleshi F, Hosseini AA (2012) Synthesis of uniform MgO/CNT nanorods by precipitation method. $\mathrm{J}$ Nanostruct Chem 3:1-5. doi:10.1186/2193-8865-3-4

Tartaj P, Morales MP, Veintemillas-Verdaguer S, Gnźalez-Carre no T, Serna CJ (2003) The preparation of magnetic nanocrystals for applications in biomedicine. Appl Phys 36:182-197

Tjong SC, Chen H (2004) Nano crystalline materials and coatings. Mat Sci Eng R 45:1-88

Venkateswarlu K, Chandra Bose A, Rameshbabu N (2010) X-ray peakbroadening studies of nanocrystalline hydroxyapatite by Williumson-Hall analysis. Phys B 405:4256-4261
Wang X, Zhao Z, Qu J, Wang Z, Qiu J (2010) Fabrication and characterization of magnetic $\mathrm{Fe}_{3} \mathrm{O}_{4}-\mathrm{CNT}$ composites. J Phys Chem Solids 71:673-676

Yan H, Zhang J, You C, Song Z, Yu B, Shen Y (2009) Influences of different synthesis conditions on properties of $\mathrm{Fe}_{3} \mathrm{O}_{4}$ nanoparticles. Mater Chem Phys 113:46-52

Zhang L, He R, Gu HC (2006) Synthesis and kinetic shape and size evolution of magnetite nanoparticles. Mater Res Bull 41: 260-267 